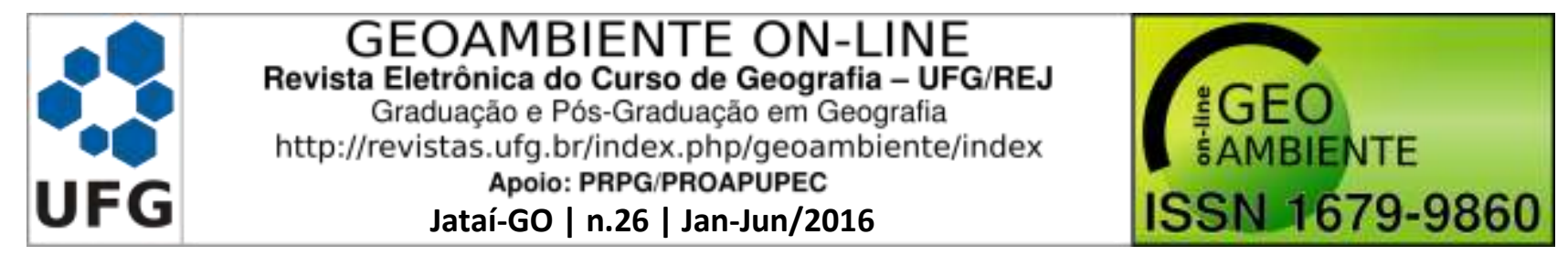

\title{
CARTOGRAFIA DO PASSADO: MEMÓRIAS COLETIVAS E FOTOINTERPRETAÇÃO DA COMUNIDADE LAGEADO GRANDE, CAMPO LARGO - PR
}

\author{
Michell Michalczyszyn ${ }^{1}$, Adelita Staniski ${ }^{2}$, Alessandro Bertolino ${ }^{3}$ \\ (1 - Pontifícia Universidade Católica do Paraná - PUC-PR, Pós-Graduando em \\ Geoprocessamento, michellmgeo@ hotmail.com; 2 - Universidade Estadual de Ponta Grossa, \\ Mestranda em Geografia, adelitasta@hotmail.com; 3 - Pontifícia Universidade Católica do \\ Paraná - PUC-PR, Docente do Curso de Engenharia Ambiental, \\ alessandro.bertolino@gmail.com)
}

Resumo: Este trabalho buscou conhecer o território pretérito da comunidade Lageado Grande no município de Campo Largo, Paraná, a partir da produção de um mapa participativo e outro mapa elaborado por meio da interpretação de uma imagem aérea da mesma região. O mapa participativo foi construído por meio da lembrança, aproximadamente 35 anos atrás, constituindo uma cartografia da representação da memória, com moradores da região. $\mathrm{O}$ segundo mapa, fruto da fotointerpretação, utiliza como referência uma fotografia aérea, monocromática, do ano de 1980. O mapeamento participativo tem feito uso das tecnologias de geoprocessamento e técnicas da cartografia e pode ser entendido como uma possibilidade de resgatar os conhecimentos tradicionais. Quanto aos resultados, comparando visualmente os mapas apresentam diferenças quanto ao número de classes. Enquanto o mapa participativo apontou 10 classes de usos da terra, o mapa da fotointerpretação adotou uma divisão em apenas 4 classes. Juntos os dois mapas ampliam a visão e possibilitam um mapeamento mais completo do local estudado.

Palavras-chave: Mapeamento participativo; Fotointerpretação; Geoprocessamento.

MAPPING THE PAST: MEMORIES AND COLLECTIVE PHOTOINTERPRETATION THE COMMUNITY LAGEADO GRANDE, CAMPO LARGO - PARANÁ - BRAZIL

Artigo recebido para publicação em 12 de Novembro de 2015

Artigo aprovado para publicação em 26 de Junho de 2016 


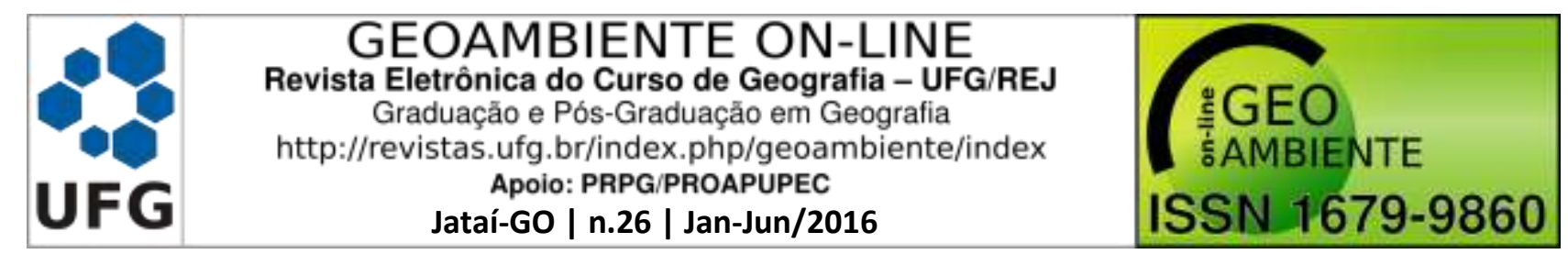

Abstract: This study searched to know the territory community past Lageado Grande in the municipality of Campo Largo, Paraná from the production of a participatory map and another map drawn up by the interpretation of an aerial image of the same region. The participatory map was constructed by memory, approximately 35 years ago, providing cartography of memory, with local residents. The second map was a photo interpretation, used as reference an aerial photograph, monochrome 1980. Participatory mapping has made use of GIS technologies and techniques of cartography and it can be understood as a chance of rescuing traditional knowledge. As for the results, visually comparing the maps differs on the number of classes. While the participatory map showed 10 classes of land uses, the map of photo interpretation showed only 4 classes. Together the two maps expand the vision and enable a more complete mapping of the studied site.

Keywords: participatory mapping; photo interpretation; Geoprocessing.

\section{CARTOGRAFÍA DEL PASADO: MEMORIAS COLECTIVAS Y FOTOINTERPRETACIÓN DE LA COMUNIDAD LAGEADO GRANDE, CAMPO LARGO, PARANÁ - BRASIL}

Resumen: Este trabajo buscó conocer el territorio pasado de la comunidad Lageado Grande, en la municipalidad de Campo Largo, Paraná, a partir de la producción de uno mapeo participativo y otro mapeo elaborado por medio de una interpretación de una imagen aérea de la misma región. El mapa participativo fue construido por medio del recuerdo, aproximadamente 35 años, constituyendo una cartografía de la memoria, con moradores de la región. El segundo mapa, fruto de la fotointerpretación, utiliza como referencia una fotografía aérea, monocromo del año 1980. El mapeo participativo tiene hecho uso de tecnologías de geoprocesamiento y técnicas de la cartografía, puede ser entendido como una posibilidad de recuperar los conocimientos tradicionales. Cuanto a los resultados, comparando visualmente los mapas presentan diferencias cuanto en el número de clases. Mientras el mapa participativo indicó 10 clases de usos de la tierra, el mapa de la fotointerpretación adoptó solamente 4 clases. Juntos los dos mapas amplían la visión y posibilitan uno mapeo más completo del local estudiado.

Palabras-clave: Mapeo participativo; Fotointerpretación; Geoprocesamiento.

\section{Introdução}




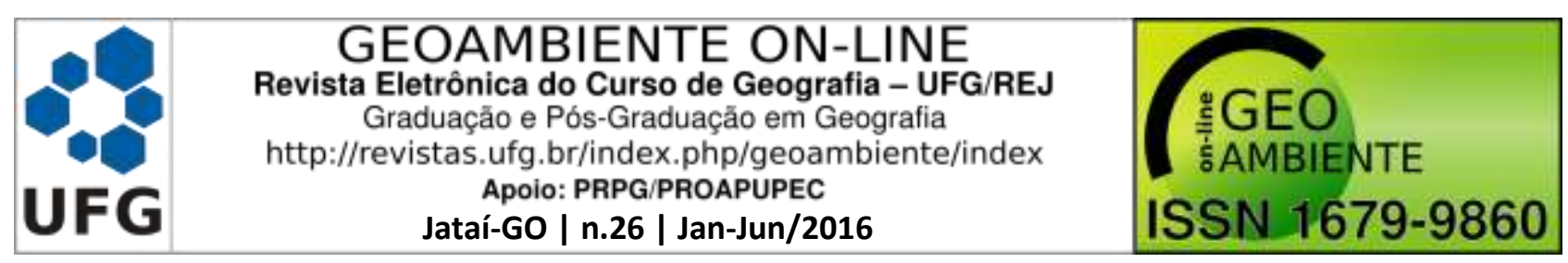

Evidenciando seu papel no desenvolvimento social e ambiental, as geotecnologias possibilitam a sistematização de mapas por meio de diferentes estratégias metodológicas. Neste sentido, os mapas participativos espacializam saberes tradicionais, que se diferenciam da cartografia tradicional por evidenciar informações qualitativas de natureza espacial e simbólica, que muitas vezes não são destacadas por agentes governamentais e pesquisadores de instituições públicas e privadas.

Esta pesquisa foi realizada em uma comunidade com características de Faxinal, expressa na estrutura da comunidade e na memória dos moradores. O sistema Faxinal é dividido basicamente em duas áreas e Chang (1988) descreve-o como uma organização camponesa que apresenta características como o criadouro e as terras de plantar. O criadouro é uma área de uso comum onde estão presentes as casas, criam-se animais soltos e onde estão os mais significativos remanescentes florestais (CHANG, 1988). E as terras de plantar são propriedades privadas, onde cada família cultiva em seu lote (LÖWEN SAHR, 2003). Essas duas áreas são separadas por cercas, portões e valos.

Apesar de preservar a estrutura e algumas práticas, a comunidade não foi reconhecida como ARESUR (Áreas Especiais de Uso Regulamentado) ${ }^{1}$. No entanto, não é tudo que permanece, há também transformações que ocorreram em um contexto histórico-econômicosocial e algumas características ainda se mantêm apenas na memória de alguns moradores. Assim, por meio da cartografia social é possível resgatar as relações entre os moradores e suas práticas econômico-ecológicas relativas ao manejo da terra que ocorria no passado.

Este trabalho buscou conhecer o território pretérito da comunidade Lageado Grande no município de Campo Largo - PR, a partir da produção de um mapa participativo ${ }^{2}$ e outro mapa elaborado por meio da interpretação de uma imagem aérea da mesma região. O mapa participativo foi construído por meio da lembrança, uma cartografia da memória, com informantes moradores da região, em um recorte temporal situado há aproximadamente 35 anos. O segundo mapa, fruto da fotointerpretação, utiliza como referência uma fotografia aérea, monocromática do ano de 1980. Com o uso destas duas metodologias, buscou-se demonstrar as diferenças e semelhança resultantes da produção dos dois mapas, bem como, resgatar o conhecimento tradicional, por meio do mapeamento participativo.

\footnotetext{
${ }^{1}$ Criado pelo decreto 3.446/1997 do Governo do Estado do Paraná que garante o direito aos Municípios (que possuem Faxinais) de receber ICMS Ecológico devido à sustentabilidade do sistema (LÖWEN SAHR, 2005).
} 


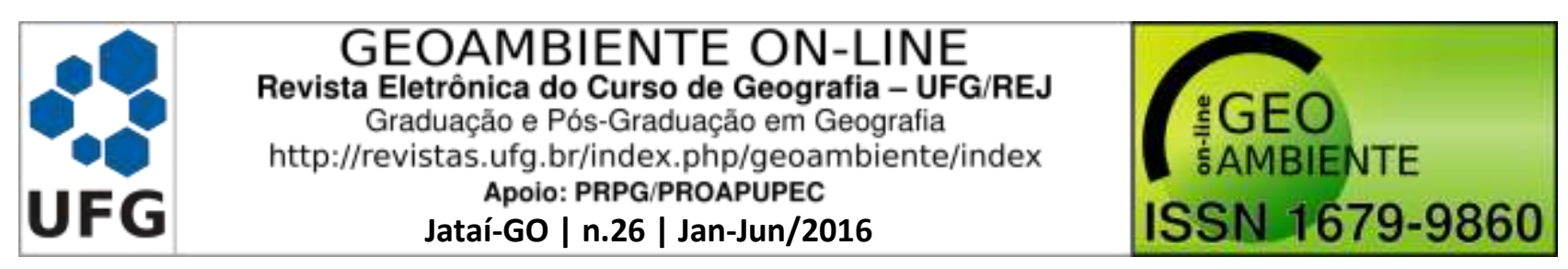

\section{Discussão Crítica}

O avanço das tecnologias de informação e o melhoramento das técnicas na ciência cartográfica apresentam novas possibilidades de servir, como um instrumento de análise social e ambiental, que se difere da cartografia tradicional por considerar e valorizar aspectos culturais e históricos de uma determinada comunidade, lugar ou território. No Brasil, a partir da década de 1990, por meio de iniciativas de instituições governamentais, organizações indígenas e universidades, iniciaram-se estudos que passaram a disseminar metodologias de mapeamento social, com o objetivo de incluir comunidades tradicionais no processo de elaboração de mapas, na perspectiva de evidenciar outras relações sobre o território (MACHADO, 2014). Isso porque os processos cartográficos tradicionais refletiam “[...] apenas o ponto de vista dos especialistas, [sem] possibilitar o envolvimento social na sua produção" (MILAGRES et al., 2010, p. 02).

A cartografia social se desliga da neutralidade e objetividade, fazendo o mapa torna-se vivo, dinâmico, subjetivo e comunitário, diferente dos mapas produzidos pela cartografia tradicional. Isto não implica dizer que um torna-se mais valioso que o outro, apenas diferem em sua gênese, haja vista que o tradicional nasce sujeito à normas, realizado por técnicos de modo vertical, enquanto o mapa social adota decisões de comum acordo entre as demais partes e propõem a construção de um espaço conhecido e comandado localmente, isto é, horizontal (TETAMANTI, 2012).

De acordo com Acselrad e Coli (2008, p. 22) "as iniciativas de mapeamento participativo variam consideravelmente em suas metodologias e terminologias." e no Brasil podem-se encontrar terminologias como: "mapeamento participativo, mapeamento participativo de uso da terra, mapeamento participativo de recursos, mapeamento comunitário, mapeamento de comunidades localizadas, etnocartografia [...]” (ACSELRAD; COLI, 2008, p.23), dentre outras iniciativas. Estas propostas têm como ponto central incluir as populações tradicionais existentes no processo de elaboração dos mapas, levando em consideração seu “conhecimento espacial e ambiental” (ACSELRAD; COLI, 2008, p. 15).

Diversos temas podem ser abordados na cartografia participativa e Herrera Hernández (2008, p. 10-11) descreve alguns exemplos como: o "mapa administrativo e de infraestrutura,

\footnotetext{
${ }^{2}$ Os dados da Cartografia participativa fazem parte da pesquisa de dissertação: STANISKI, A. Os saberes mateiros das comunidades tradicionais da Região Serra das Almas, Paraná: histórias de vida e paisagens, com defesa em 2016.
} 


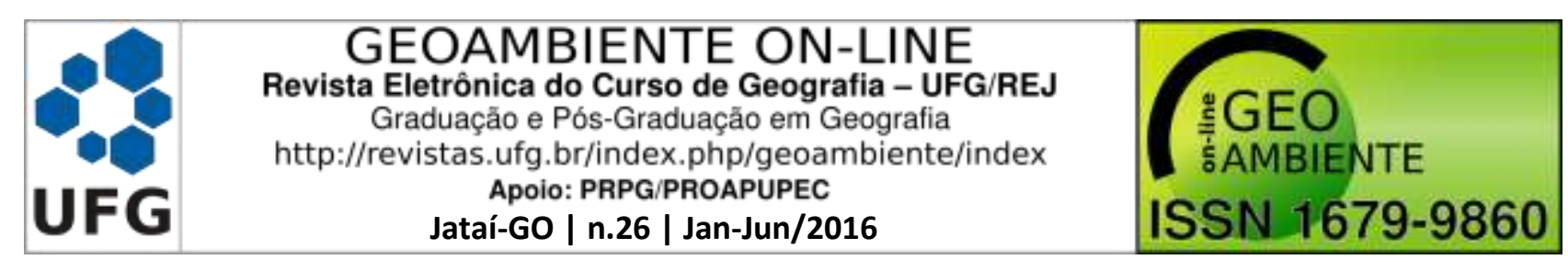

mapa ecológico, mapa econômico, mapa de conflito, mapa de rede e de relações", entre outros. Ainda segundo o mesmo autor, é possível fazer três tipos de mapa quanto ao período histórico: do passado, presente e futuro. O mapa do passado se configura como um mapa histórico que é importante para reconhecer as mudanças no contexto e resgatar a memória coletiva de seus habitantes.

O mapeamento participativo tem feito uso das tecnologias de geoprocessamento e técnicas da cartografia. As informações levantadas em campo podem ser tratadas em uma abordagem mais tecnológica, combinando métodos tradicionais com tecnologias de geoprocessamento, tais como, receptores de GPS (Sistema de Posicionamento Global), SIG's (Sistemas de Informações Geográficas) e o sensoriamento remoto. Neste sentido, com a elaboração de mapas, construídos através do mapeamento participativo é possível "raciocinar espacialmente de maneira coletiva" (JOLIVEAU, 2008, p. 52), possibilitando a criação de novas perspectivas de representação espacial, construída por diferentes sujeitos sociais, com viabilidade de transformar o espaço vivenciado pelos seus moradores em um espaço de expressão visual, capaz de afirmar suas culturas.

Diante de um grande número de metodologias e terminologias utilizadas na cartografia social, este trabalho adota o conceito de mapeamento participativo como uma ferramenta capaz de "construir mapas congregando o conhecimento técnico próprio da cartografia clássica [...] com os conhecimentos de mundo e as experiências de comunidades tradicionais, movimentos sociais, entre outros grupos, como os usos do território" (BARGAS; CARDOSO, 2015, p. 475).

No trabalho se utiliza também técnicas da fotointerpretação, que é definida como o ato de examinar fotografias aéreas com o objetivo de identificar objetos e determinar o seu significado. Quando não é possível caracterizar o objeto na foto é preciso apoiar-se em dados conhecidos, como por exemplo, conhecimento In loco da região fotografada. Na interpretação, o intérprete pode extrair a informação dependendo da sua necessidade, da sua capacidade e experiência de análise ou da qualidade do material avaliado, podendo assim, preparar um mapa final preciso ou impreciso, completo ou parcial. O pesquisador deve também levar em consideração alguns critérios na interpretação, como tamanho, forma, densidade, posição, sombreamento, tonalidade, declividade e textura (LOCH, 2008).

\section{Metodologia}




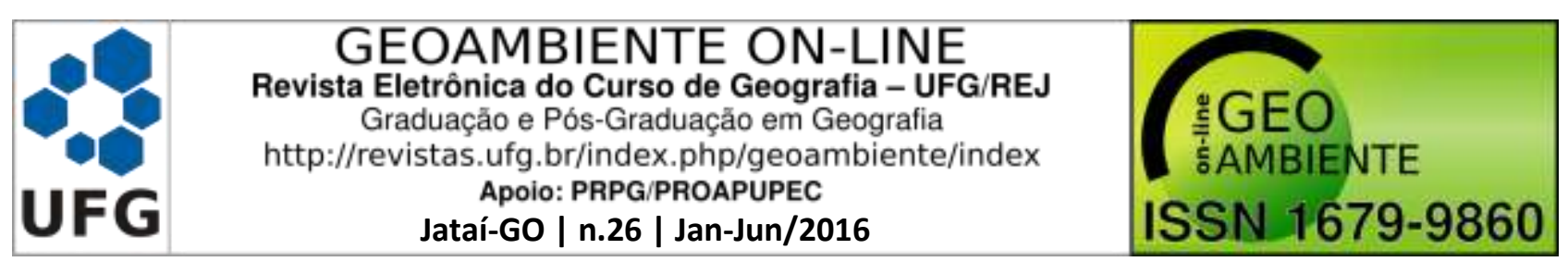

A comunidade situa-se a cerca de $50 \mathrm{Km}$ do centro do município de Campo Largo, Paraná. É composta por aproximadamente 30 famílias as quais sobrevivem de variadas formas de renda, como agricultura, carpintaria, aposentadoria, diarista, funcionário público, assalariados em empresa de reflorestamento de Pinus taeda, apicultura, piscicultura, carvoaria, chacareiro, entre outras.

A pesquisa teve início com uma revisão de literatura, partindo então para uma aproximação com os moradores, esta permitiu conhecer a realidade da comunidade e a interação destes com o lugar onde vivem. A partir deste contato em busca de informações gerais sobre a comunidade é que foi possível localizar os informantes-chave com os quais foi realizado o mapeamento participativo.

O mapeamento participativo foi produzido a partir de um mapa base, ao qual foram acrescidas informações pelos entrevistados. O mapa base foi elaborado pela obtenção de uma imagem orbital do software Google Earth, construído com referenciais cartográficos e geodésicos. Este mapa base serviu para apoiar o trabalho de campo, auxiliando os entrevistados, na localização das terras e seus respectivos usos. Partindo do uso da terra em que se via na imagem atual, o informante conseguia associar a área ao seu proprietário, lembrando várias histórias e usos do passado, assim as delimitações atuais serviram como base para a localização, no entanto, as várias parcelas de uso acabaram tomando outras formas, pois a partir do momento em que reconheciam a área, os entrevistados já apontavam no papel outros lugares que também tinham mesmo uso.

Para recobrir toda a área de estudo utilizou-se uma cena com altitude do ponto de visão de 5,70 quilômetros, georreferenciadas por meio do software ArcGIS 10.2.1 com base cartográfica UTM, SIRGAS 2000 com a utilização de uma camada de pontos de controle coletados com um aparelho receptor GPS (Sistema de Posicionamento Global) Garmin eTrex 30. Foram amostrados um total de 25 pontos de controle, distribuídos ao longo da área de estudo, coletados em sua maioria no encontro (encruzilhadas) das estradas, em pontos notáveis. Deste total, apenas 13 foram utilizados para referenciar a fotografia aérea.

O período temporal buscado entre os informantes, se deu em decorrência de que as principais transformações ocorridas no modo de vida rural estão relacionados a modernização da agricultura, a partir da década de 70. Como também nas informações encontradas no momento de aproximação com a comunidade, a qual relatou que o Pinus taeda foi inserido na 


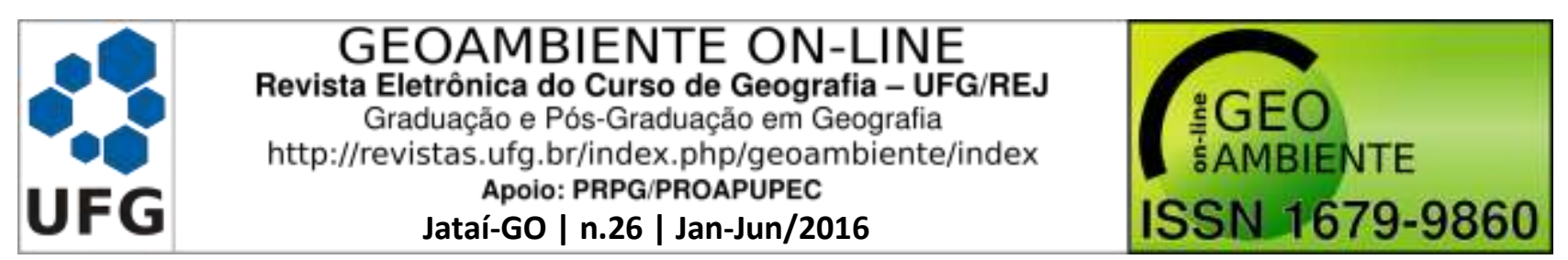

região a aproximadamente 30 anos e a energia elétrica foi instalada na década de 90, transformações que configuram a paisagem atual encontrada.

Assim, para realizar a cartografia do passado dois moradores da área estudada, com idade entre 50 e 70 anos, foram chamados a reconhecer e se manifestar sobre o espaço onde vivem. Esta seleção ocorreu a partir de alguns critérios, como: viver a pelo menos 50 anos na comunidade, ter sempre trabalhado na agricultura e ter sido indicado por outros moradores da comunidade como grandes conhecedores da região, sendo assim, denominados como informantes- chave. Amparados pela vivência cotidiana do território, foram os responsáveis pela reprodução dos croquis que caracterizavam o meio físico e social onde estão inseridos.

O local de estudo abrangeu além das propriedades dos informantes e cada um foi responsável pela elaboração de um desenho. Nem toda a informação utilizada para a confecção do mapa final foi registrada em um único croqui e as informações foram complementadas. Herrera Hernández (2008) lembra que a construção do conhecimento através da elaboração coletiva de mapas, desata processos de comunicação entre os participantes e põem em evidência diferentes tipos de saberes que se mesclam para poder chegar a uma imagem coletiva do território.

No levantamento das informações em campo, utilizaram-se o mapa base, uma folha de papel manteiga sobre o mapa base e um lápis para traçar pontos, linhas e polígonos (Figura 1). Foi possível, assim, representar o espaço vivido e habitado pelos informantes, onde o pesquisador teve o papel de orientar, no sentido de que a representação registrada ficasse materializada, pois a complexidade para interpretar o mapa base poderia tornar difícil a participação dos entrevistados, que muitas vezes não estão acostumados com esta metodologia.

Figura 1- Detalhe da produção do mapa participativo pelos moradores.

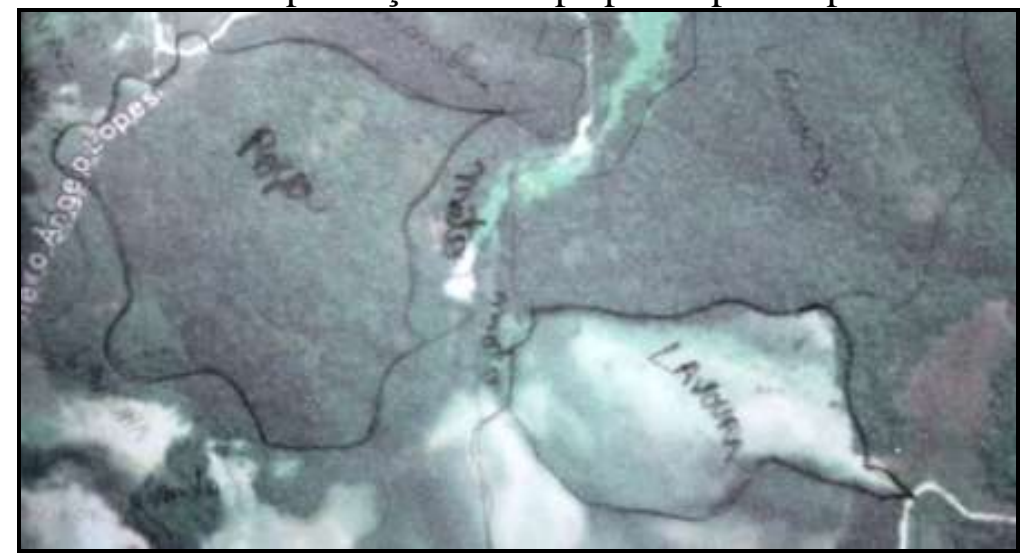




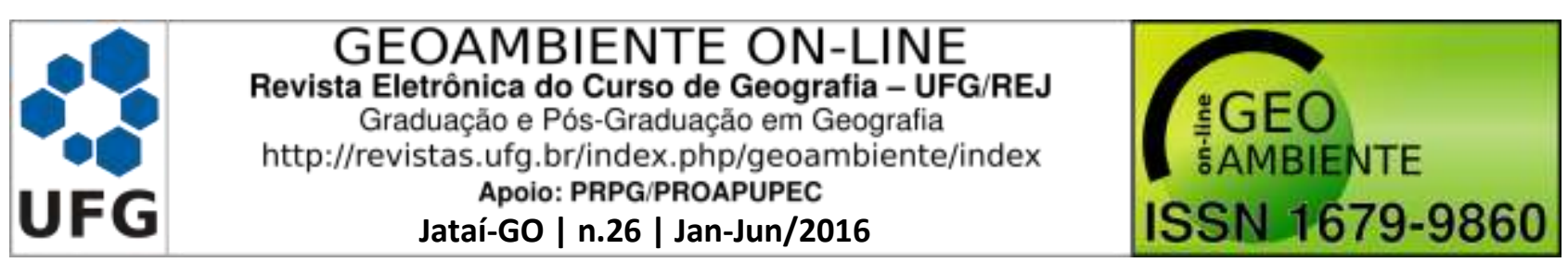

Fonte: Diversas. Org: os autores, 2015.

Desta forma, um mapa do passado econômico-ecológico com informações a respeito do uso da terra foi sendo identificado e delimitado pelos pesquisados. Posteriormente o registro produzido pelos moradores foi vetorizado manualmente no software ArcGIS 10.2.1. A hidrografia local foi vetorizada da carta topográfica MI2841-2 Três Córregos na escala 1:50.000, material que encontra-se disponível no site do Instituto de Terra, Cartografia e Geociências (ITCG) do estado do Paraná.

Um segundo mapa foi gerado utilizando como referência uma fotografia aérea monocromática datada de 27 de junho do ano de 1980, também disponível no site do ITCG na escala 1: 25.000. Esta fotografia foi dotada de referência geográfica UTM, SIRGAS 2000. Para referenciar esta fotografia foram utilizados os mesmo pontos de controle que serviram para referenciar o mapa base, visto que, poucas mudanças ocorreram nos traçados das estradas. A fotointerpretação foi realizada pelo pesquisador, que examinou os aspectos pertinentes à cobertura vegetal e às atividades econômicas ligadas ao uso da terra, tais como: vegetação densa, vegetação rala e agricultura. Esta classificação foi baseada no manual do uso da terra do Instituto Brasileiro de Geografia e Estatística (IBGE, 2013).

Posteriormente os dois mapas foram analisados, a fim de comparar as possíveis diferenças entre informações e possibilidades de complementação, que podem surgir quando se aplicam métodos distintos.

\section{Resultados}

Com as informações coletadas em campo, foi elaborado o mapa participativo da comunidade Lageado Grande em Campo Largo/PR (Figura 2). Este mapa traz informações pertinentes ao uso da terra, de forma a contemplar aspectos econômicos-ecológicos, como as áreas destinadas à atividade agrícola e os estágios da vegetação, com um total de 10 classes (Quadro 1).

Com relação à agricultura no período em questão (cerca de 35 anos atrás) caracterizava-se como uma agricultura tradicional, com pouca ou nenhuma mecanização, onde para o preparo da terra era feito o roçado e queimava-se para plantar, plantava-se de tudo um pouco (milho, feijão, batata, batata doce, mandioca, arroz) principalmente para subsistência com o excedente comercializado. No mapa esta informação ficou agrupada em 


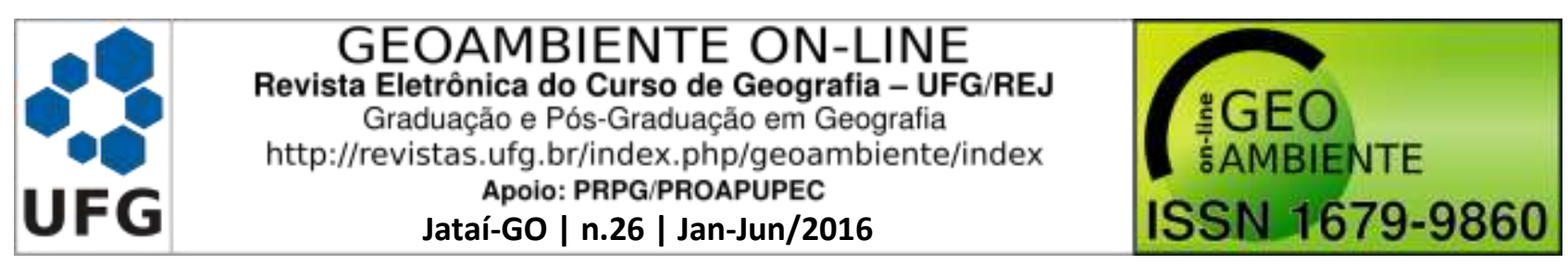

uma única classe: roça (que representa um total de $38 \%$ em relação ao total da área de estudo).

Figura 2- Mapa Participativo

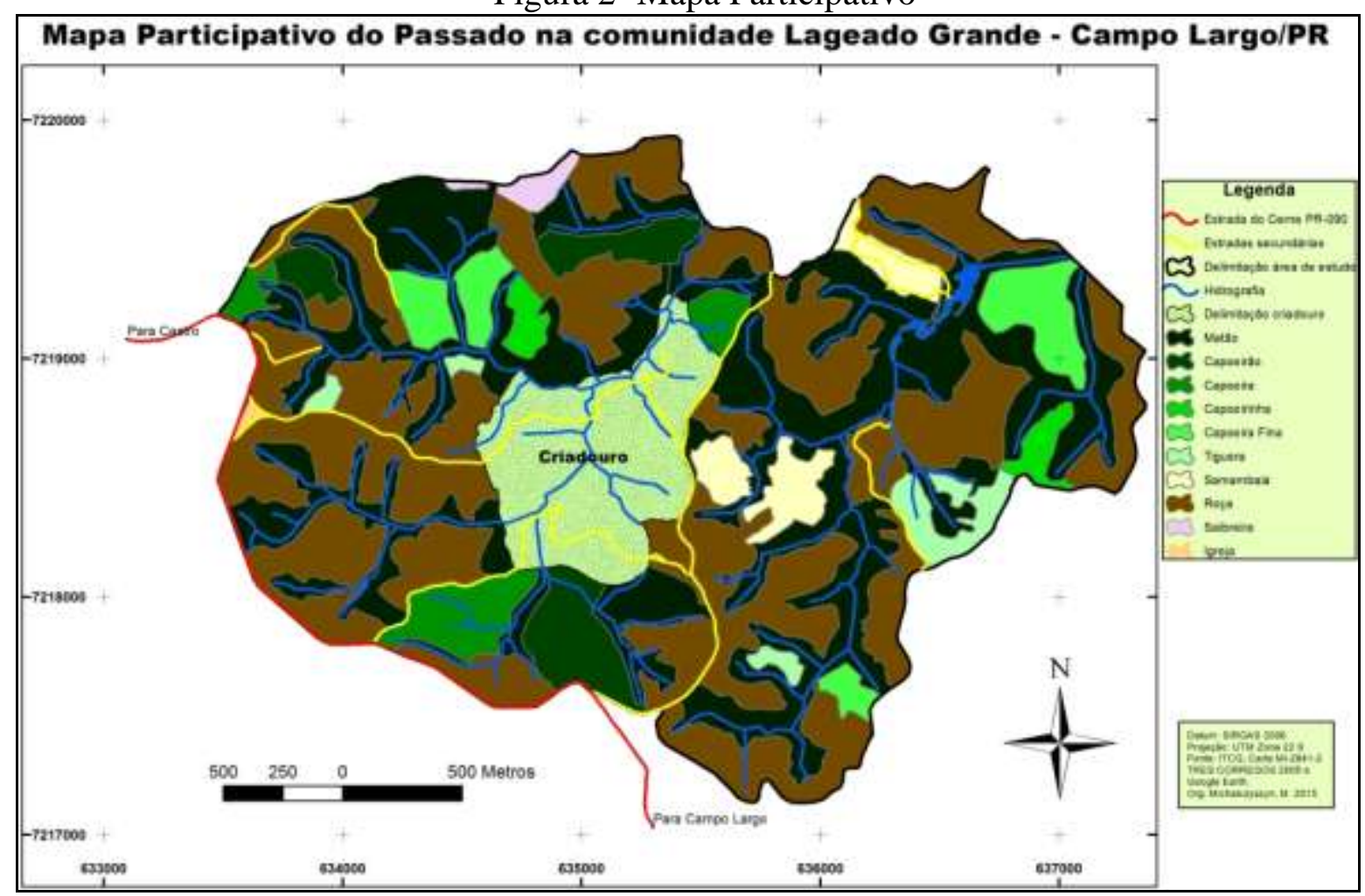

Fonte: Diversas. Org. MICHALCZYSZYN (2015)

Quadro 1- Porcentagem do uso da terra mapa participativo.

\begin{tabular}{|c|c|}
\hline Classes & $\%$ \\
\hline Roça & 38 \\
\hline Matão & 33 \\
\hline Delimitação criadouro & 10 \\
\hline Capoeirão & 5 \\
\hline Capoeira Fina & 4 \\
\hline Capoeira & 3 \\
\hline Samambaiá & 3 \\
\hline Tiguera & 2 \\
\hline Capoeirinha & 1 \\
\hline Saibreira/Igreja & 1 \\
\hline
\end{tabular}

Fonte: Classes relatadas pelos informantes-chave da comunidade, 2015. Org. MICHALCZYSZYN, 2015.

As classes relativas ao estágio da vegetação foram divididas em 6 classes, são elas: Tiguera, Capoeirinha fina, Capoeirinha, Capoeira, Capoeirão e Matão. Essa grande 


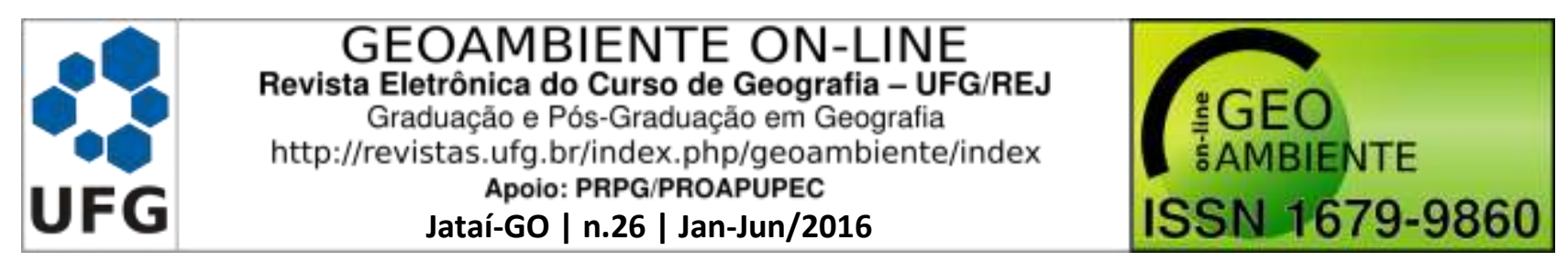

quantidade de classes se explica pelo conhecimento com relação ao estágio sucessional de desenvolvimento da vegetação que os moradores possuem. Tais estágios existem porque quando se corta a vegetação nativa para a agricultura, o lugar pode ser utilizado por um período contínuo ou temporário e nos anos seguintes se o agricultor deixar de plantar ou descansar a terra (pousio) a vegetação vai retornando naturalmente, a ponto de formar, por exemplo, uma Capoeira fina que varia de 3 a 6 anos de idade ou um Matão, com idade superior a 50 anos. A diferença, segundo os moradores, se dá principalmente pala idade da vegetação (Quadro 2). No entanto, outros critérios são utilizados indiretamente para classificar, como diâmetro das árvores, altura média, ambientes e situações geográficas.

Quadro 2- Classificação da vegetação por idade.

\begin{tabular}{|c|c|}
\hline Vegetação & Idade \\
\hline Tiguera & 1 a 2 anos \\
\hline Capoeirinha fina & 3 a 6 anos \\
\hline Capoeirinha & 7 a 10 anos \\
\hline Capoeira & 11 a 18 anos \\
\hline Capoeirão & 19 a 49 anos \\
\hline Matão & Acima de 50 anos \\
\hline
\end{tabular}

Fonte: Informantes-chave da comunidade. Org: os autores, 2015.

A classe criadouro, com $10 \%$ de ocupação em ambos os mapas, identificada e delimitada pelos participantes no mapa participativo serviu também como base de delimitação para o mapa da fotointerpretação. Esta classe é um espaço característico do sistema faxinal, definido por Löwen Sahr (2003, p. 13) como um espaço de uso comum "onde a comunidade faxinalense habita e cria seus animais. Dentro do criadouro existem várias espécies de árvores nativas [...]”. Assim, esta área é caracterizada por abrigar a maioria das casas da área de estudo, além de representar um importante remanescente de vegetação nativa. A delimitação do criadouro é feita por cercas e valos (Figura 3) (valetas que podem chegar até a 2 metros de profundidade, abertas à enxada e cortadeira), os moradores utilizaram-se de rios, estradas e o declive do terreno para delimitar esta área, pois a função deste cercamento é evitar que os animais fujam, estragando a agricultura. Na imagem aérea são identificáveis algumas casas neste local, visível também uma grande concentração de vegetação.

A classe Samambaiá com 3\% de ocupação é explicada como uma área onde foi derrubada a vegetação para agricultura, no entanto, não é uma terra fértil, assim, é deixada de 


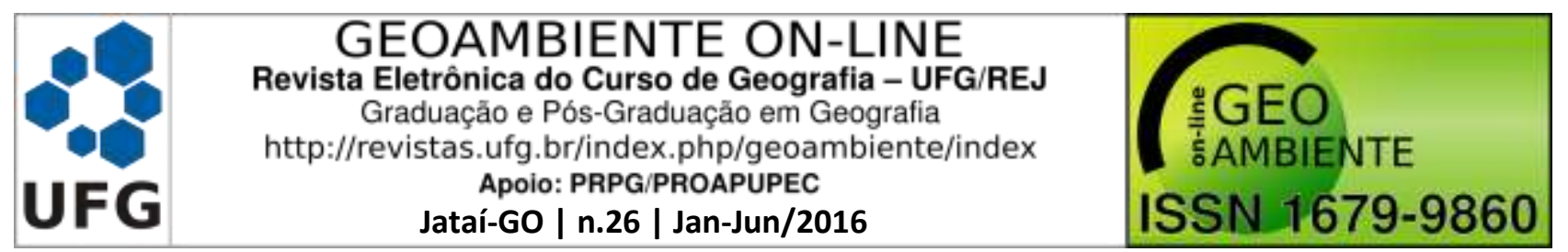

lado formando um Samambaiá (Pteridium aquilinum (L.) Kuhn Var). A classe Saibreira com $1 \%$ é local onde retira-se material (saibro) para arrumar as estradas.

Utilizando as técnicas de fotointerpretação de fotografias aéreas foi elaborado outro mapa a partir da interpretação e classificação visual do pesquisador (Figura 4). Na fotografia aérea foi possível identificar pelo menos três classes distintas de uso da terra: Agrícola, Floresta Densa e Floresta Rala.

Figura 3- Detalhe do valo na comunidade Lageado Grande, Campo Largo, Paraná

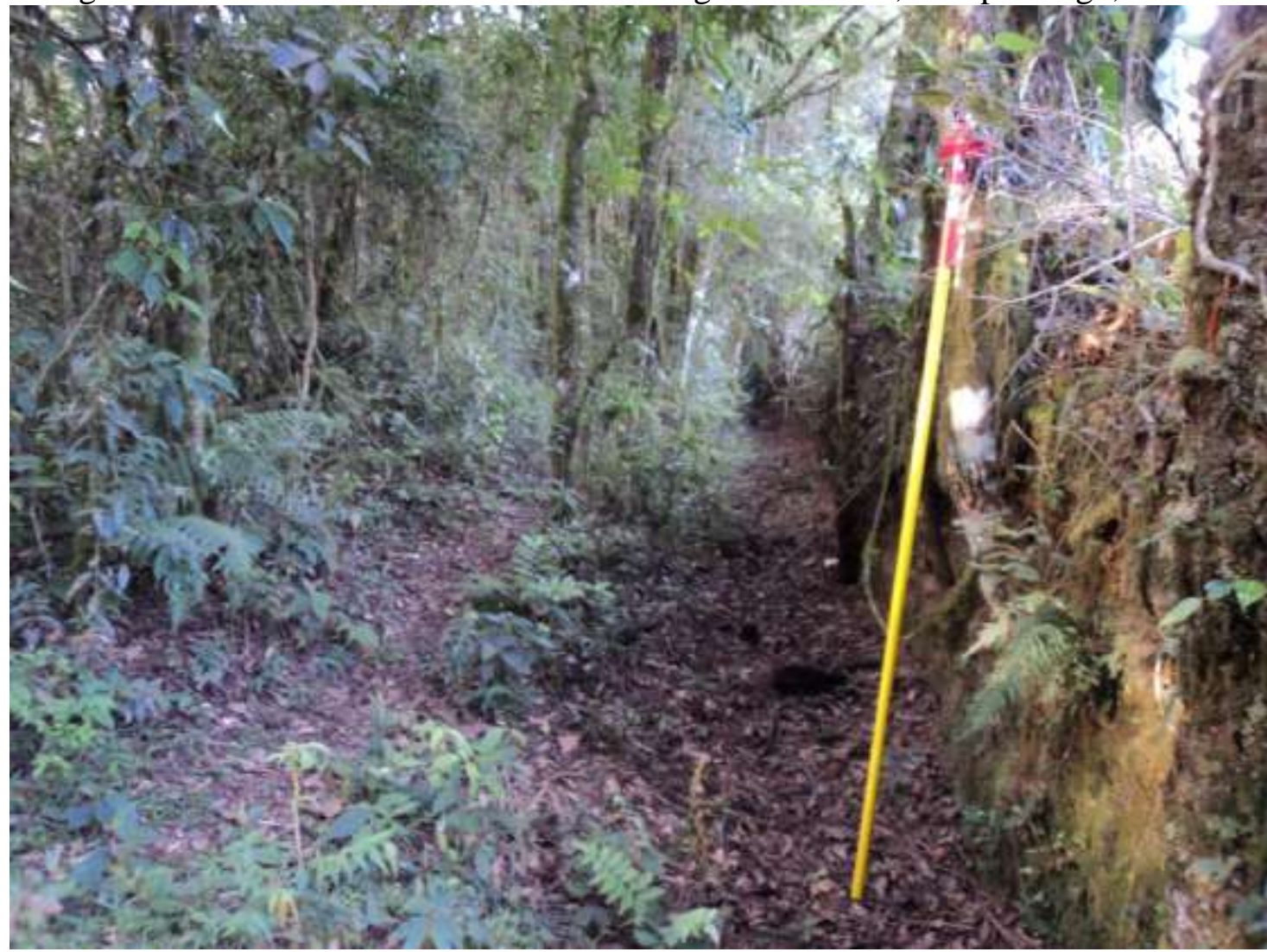

Fonte: os autores, 2015.

As categorias de uso da terra foram adaptadas do Manual do uso da terra do Instituto Brasileiro de Geografia e Estatística (IBGE) e possuem as seguintes características:

- Agrícola: É composta por áreas heterogêneas constituídas pelo plantio de culturas temporárias e perenes (IBGE, 2013). Os padrões correspondentes à agricultura segundo Loch (2008, p 37) devem apresentar "formas regulares, ausência de sombra, textura aveludada, tonalidade clara ou intermediária". 


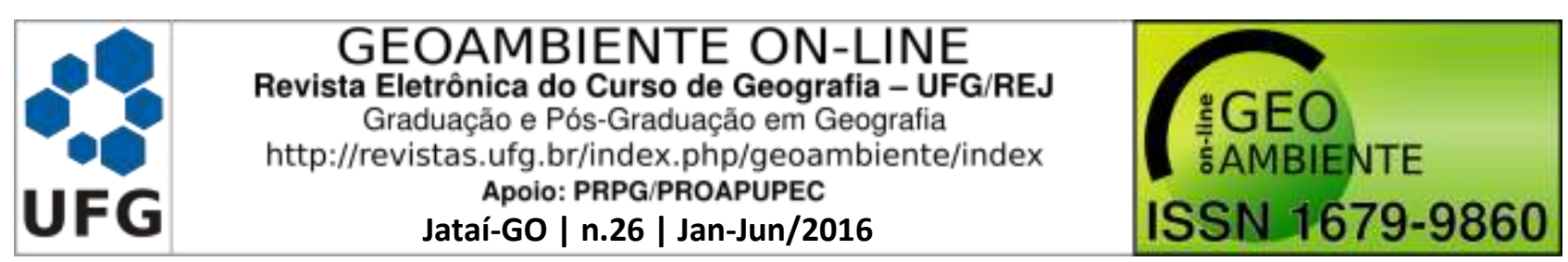

- Floresta Densa: Distingue-se pela formação composta por elementos arbóreos em sua maioria densos e de estrutura florestal contínua. Muitas vezes associada a cursos de água e declives mais acentuados (IBGE, 2013).

- Floresta Rala: Floresta aberta, estrutura florestal com diferentes graus de descontinuidade da cobertura superior, caracterizada por possuir uma formação com árvores de estrutura mais aberta e/ou alteração antrópica. (IBGE, 2013).

Figura 4- Mapa fotointerpretação

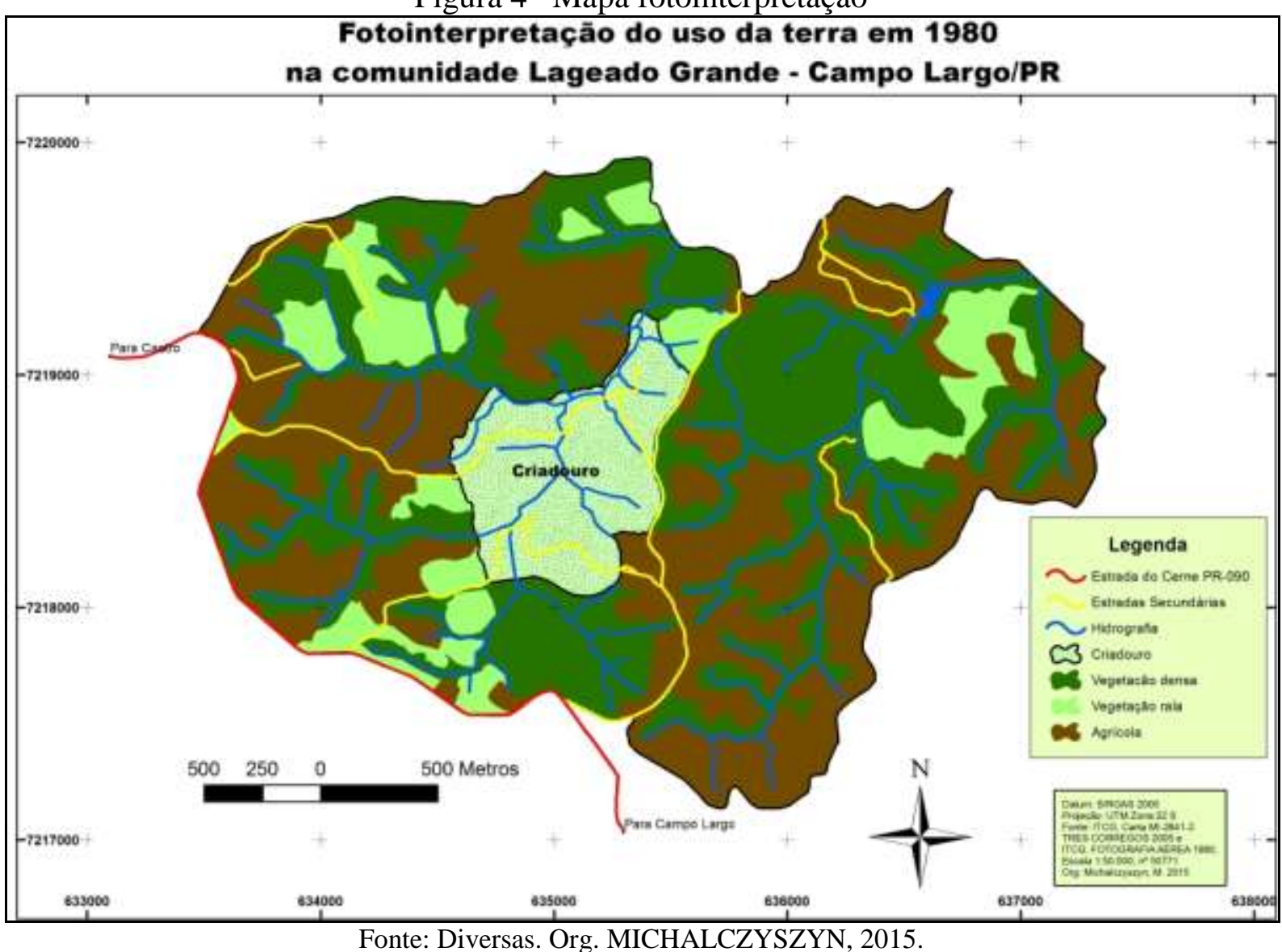

A classe criadouro, com $10 \%$ de ocupação, identificada e delimitada pelos participantes no mapa participativo, serviu também como base para o mapa da fotointerpretação. $\mathrm{Na}$ imagem aérea é visível uma maior concentração de vegetação, bem como, algumas casas nesta região.

As classes de uso da terra demonstram que as áreas de vegetação densa e rala apresentam um percentual de $48 \%$ do total, superior a área agrícola que reflete $42 \%$ como demonstra o (Quadro 3). 


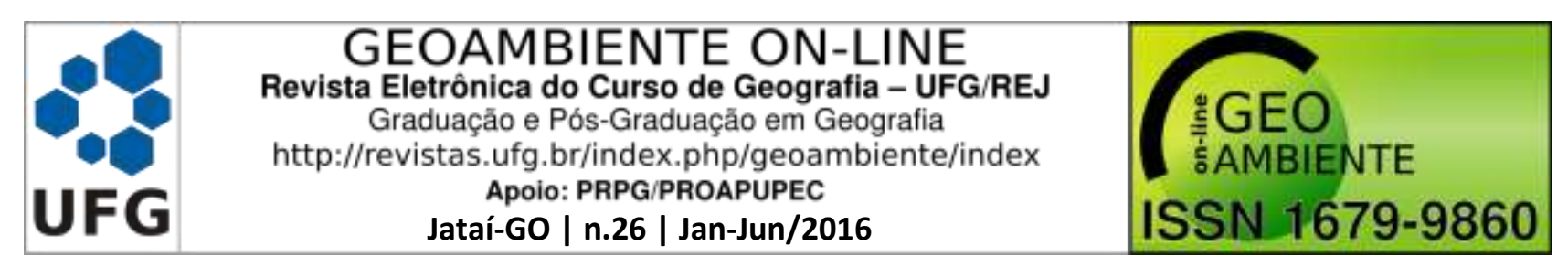

Quadro 3 - Porcentagem do uso da terra mapa fotointerpretação.

\begin{tabular}{|c|c|}
\hline Classes & $\%$ \\
\hline Agrícola & 42 \\
\hline Vegetação densa & 37 \\
\hline Vegetação rala & 11 \\
\hline Delimitação criadouro & 10 \\
\hline
\end{tabular}

Fonte: Classes IBGE, 2013. Org. MICHALCZYSZYN, 2015.

Dispondo dos dois mapas, um construído a partir da cartografia participativa e o outro elaborado utilizando-se técnicas da cartografia tradicional (fotointerpretação), é possível comparar os dados levantados. O objetivo desta comparação não é julgar se o mapa produzido pelo viés da cartografia social é uma referência confiável, visto que a técnica da fotointerpretação também não é isenta de erros, pois as informações retiradas da fotografia dependem da capacidade técnica e do conhecimento que o intérprete tem. A finalidade é levantar as possíveis diferenças e semelhanças que um e outro podem demonstrar quando se empregam duas metodologias distintas e que podem se complementar na produção do conhecimento.

Quanto à vegetação, para o mapa participativo, quando agrupadas, as 6 classes de vegetação (Tiguera, Capoeirinha fina, Capoeirinha, Capoeira, Capoeirão e Matão) correspondem a $48 \%$ de uso da terra em relação ao total da área estudada. Para o mapa da fotointerpretação, quando agrupadas as 2 classes de vegetação (Vegetação densa e Vegetação rala) o valor também corresponde a $48 \%$ de uso da terra. As áreas de vegetação que apresentam maior coincidência nos dois mapas estão presentes ao longo das margens dos rios (matas ciliares) e em alguns capões, principalmente na porção sul e nordeste.

Quanto à atividade econômica, a roça caracterizada no mapa participativo representa $38 \%$ de uso da terra em relação ao total da área de estudo. E a classe agrícola no mapa da fotointerpretação corresponde a $42 \%$ de uso da terra em relação ao total da área de estudo. Nota-se assim, uma semelhança nos mapas, inclusive em relação à localização espacial desta classe, presente nas áreas menos declivosas.

Assim, com o uso destas duas metodologias, mapeamento participativo e fotointerpretação, algumas semelhanças e diferenças são encontradas. Quanto às semelhanças, as classes roça e agricultura têm uma forte relação quanto à localização e o Matão e Vegetação densa, também apresentam um padrão que se distribui principalmente ao longo das 


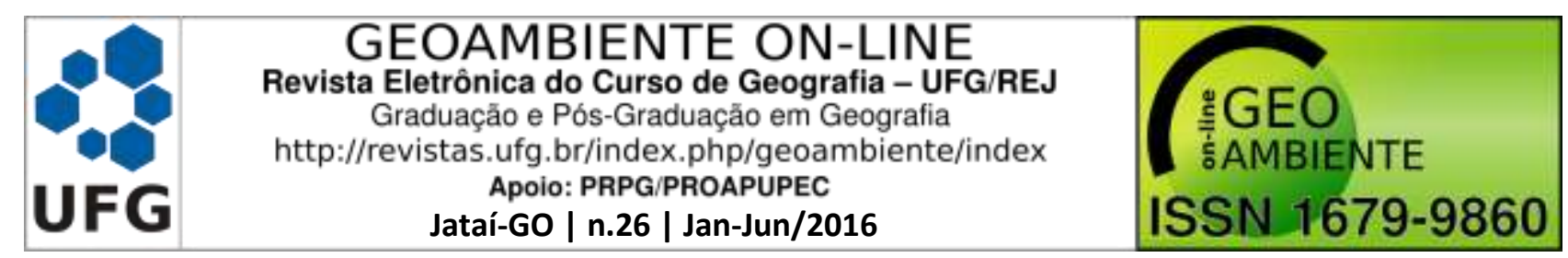

margens dos rios. Em relação às diferenças, os mapas resultam de duas técnicas diferentes e quando comparados visualmente, apresentam diferenças quanto ao número de classes. Enquanto o mapa participativo apresenta 10 classes de usos da terra, o mapa da fotointerpretação adotou uma divisão em apenas 4 classes.

\section{Considerações finais}

As duas metodologias utilizadas neste trabalho conseguiram alcançar seu objetivo que era conhecer o território da comunidade Lageado Grande no município de Campo Largo PR. No entanto, o mapa produzido pela cartografia participativa se mostrou mais rico em detalhes, apresentando uma classificação que aponta não somente os tipos de uso, mas relacionaram às áreas as espécies vegetais (quando separa áreas de Capoeira da Capoeirinha) e relaciona as espécies ao solo, quando apresenta áreas de "Samambaiá" ao invés de agrupá-la à classificação de tiguera ou capoeirinha. $\mathrm{O}$ mapa produzido pela fotointerpretação também atingiu os resultados esperados, quanto às classificações e uso da terra. Juntos os dois mapas ampliam a visão e possibilitam um mapeamento mais completo do local estudado.

\section{Referências}

ACSELRAD, H.; COLI, L. R. Disputas territoriais e disputas cartográficas. In: ACSELRAD, H. (Org). Cartografias Sociais e Território. Rio de Janeiro: Universidade Federal do Rio de Janeiro /IPPUR, 2008. Disponível em 〈http://www.ettern.ippur.ufrj.br/publicacoes/58/cartografias-sociais-e-territorio >. Acesso em: $15 / 07 / 2015$.

BARGAS, J. de K. R.; CARDOSO, L. F. C. e. Cartografia social e organização política das comunidades remanescentes de quilombos de Salvaterra, Marajó, Pará, Brasil. Boletim do Museu Paraense Emílio Goeldi. Ciências Humanas, Belém, v. 10, n.2, p. 469-488, maioago. 2015. Disponível em: <http://www.scielo.br/pdf/bgoeldi/v10n2/2178-2547-bgoeldi-1002-00469.pdf>. Acesso em: 04/10/2015.

CHANG, M. Y. Sistema Faxinal: uma forma de organização camponesa em desagregação no centro-sul do Paraná. Londrina: IAPAR, 1988. 121 f. (Boletim).

HERRERA HERNÁNDEZ, J. M. Cartografía social. Tenerife: Universidad de la Laguna, Facultad de Ciencias Políticas y Sociales, 2008. Disponível em: 


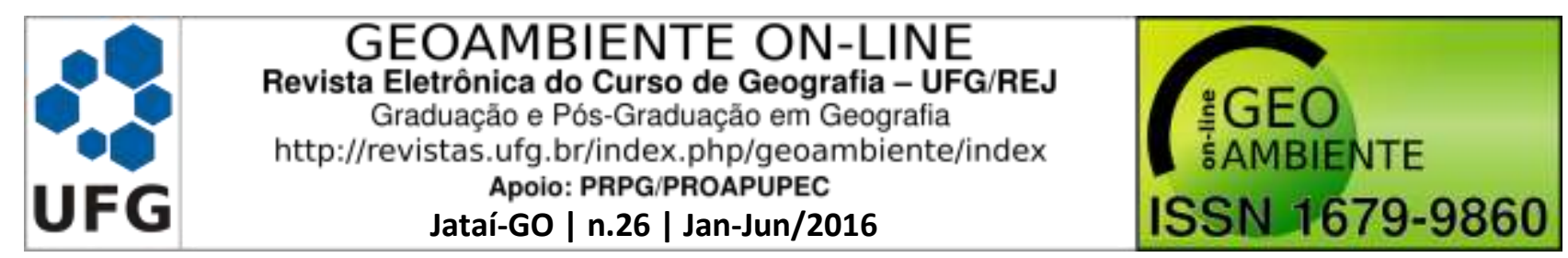

<http://www.juanherrera.files.wordpress.com/2008/01/cartografia-social.pdf $>$. Acesso em: 01/10/2015.

IBGE. Instituto Brasileiro De Geografia e Estatística. Manual técnico de uso da terra. Rio de Janeiro, 3 ed., IBGE, 2013. Disponível em: <ftp://geoftp.ibge.gov.br/documentos/recursos_naturais/manuais_tecnicos/manual_uso_da_ter ra.pdf>. Acesso em: 05/10/15.

ITCG. Instituto de Terras Cartografia e Geociências. Fotografia aérea. 1980; escala 1:50.000; $\mathrm{n}^{\mathrm{o}}$ 50771. Disponível em:<http://www.geo.pr.gov.br/ms4/itcg/geo.html\#>. Acesso em: 08/07/2015.

ITCG. Instituto de Terras Cartografia e Geociências. Carta Topográfica. Disponível em: <http://www.itcg.pr.gov.br/arquivos/File/Produtos_DGEO/Mapeamento_Sistematico/Cartas Topograficas_IBGE/Raster/50/Cartas_50/MI_2841_2_TRES_CORREGOS_2005.zip>.

Acesso em: 25/06/2015.

JOLIVEAU, T. O lugar dos mapas nas abordagens participativas. In: ACSELRAD, H. (Org.). Cartografias Sociais e Território. Rio de Janeiro: Universidade Federal do Rio de Janeiro $\quad$ /IPPUR, 2008. p. 45-69. Disponível em: $<$ http://www.ettern.ippur.ufrj.br/publicacoes/58/cartografias-sociais-e-territorio>. Acesso em: $15 / 07 / 2015$.

LOCH, C. A interpretação de imagens aéreas. 5. ed. Florianópolis: Editora da UFSC, 2008. LÖWEN SAHR, C. L.; IEGELSKI, F. O Sistema Faxinal no Município de Ponta Grossa: Diretrizes para a preservação do ecossistema, do modo de vida, da cultura e das identidades das comunidades e dos espaços faxinalenses. 1ed. Ponta Grossa: Prefeitura Municipal de Ponta Grossa, 2003.

LÖWEN SAHR, C. L. Preservação e revitalização do Sistema Faxinal na Região da Mata de Araucária do Paraná: um Projeto Extensionista. Revista Conexão UEPG, v. 1, n.1, p. 42-46, 2005. Disponível em: $<$ http://www.revistas2.uepg.br/index.php/conexao/article/view/3888/2749>. Acesso em $25 / 09 / 2015$.

MACHADO, M. C. Mapeamento Cultural e Gestão Territorial de Terras Indígenas: O uso dos Etnomapas. 2014. 120 f. Dissertação (Mestrado em geografia) Universidade de Brasília, Brasília, 2014. Disponível em: 


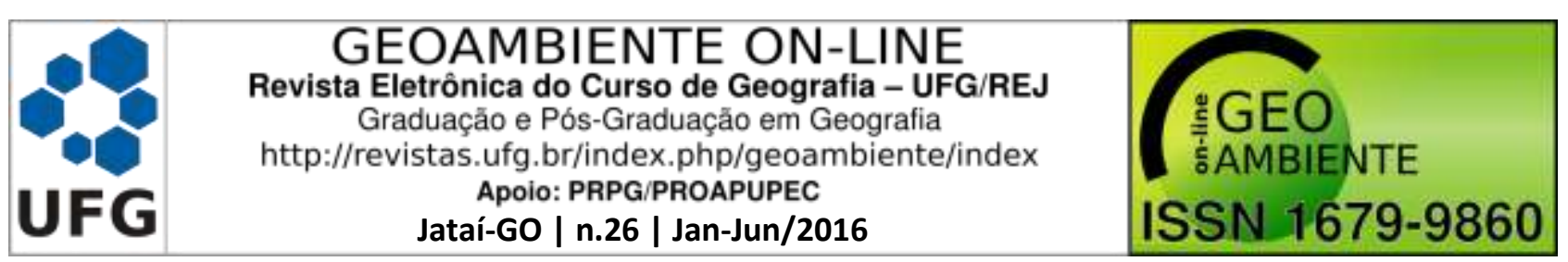

<http://repositorio.unb.br/bitstream/10482/17388/1/2014_MelineCabralMachado.pdf $>$.

Acesso em: 25/09/2015.

MILAGRES, C. S. F.; NETO, J. A. F.; SOUSA, D. N. de. O uso dos Sistemas de Informação Geográfica Participativos (PGIS'S) na representação territorial de comunidades. In: Anais do VIII Congresso Latinoamericano de Sociología Rural, Porto de Galinhas, 2010.

TETAMANTI. J. M. D. Cartografía Social. Herramienta de intervención e investigación social compleja. El vertebramiento inercial como proceso mapeado. In: TETAMANTI, J. M. D. et.al. (Org). Cartografía social: investigaciones e intervención desde las ciencias sociales, métodos y experiencias de aplicación. 1a ed. Comodoro Rivadavia: Universitaria de la Patagonia, 2012. 